Thorax (1972), 27, 1.

\title{
Saphenous vein bypass for direct coronary revascularization
}

\author{
D. N. ROSS, L. GONZALEZ-LAVIN ${ }^{1}$, and T. FRAZIER \\ Department of Surgery, Institute of Cardiology and National Heart Hospital, London W.1
}

\begin{abstract}
The surgical approach to myocardial revascularization has been undertaken on the same basis as in peripheral vascular surgery. Aorta to coronary saphenous vein bypass has been found to be one of the best methods of providing immediate augmentation of coronary blood flow. Thirty-eight patients have been operated upon. The hospital mortality was $5.3 \%$ and the total mortality has been $13.2 \%$ in a follow-up extending one month to two years. Among the survivors, $90 \%$ had excellent initial results with complete disappearance of symptoms and marked improvement in exercise tolerance. The authors advocate the saphenous vein bypass as the procedure of choice for elective coronary revascularization.
\end{abstract}

Our present attitude to the problem of myocardial ischaemia due to coronary atherosclerosis is to regard the heart as any organ or part of the body affected by vascular occlusive disease. Consequently, our surgical approach to this condition is undertaken on the same basis as in peripheral vascular surgery.

With the advent of coronary arteriography (Sones, Shirey, Proudfit, and Westcott, 1959 ; Sones and Shirey, 1962) an accurate anatomic diagnosis has become available, making it possible to select properly the patients for coronary revascularization and apply well-established vascular surgical techniques to the coronary arteries. Nowadays, among all procedures for coronary revascularization, saphenous vein bypass can be performed with low mortality and good initial result. The purpose of this presentation is to report our experience using this method as an elective operation for myocardial revascularization.

\section{CLINICAL MATERIAL}

Aorta to coronary saphenous vein bypass grafts have been performed in 38 patients at Guy's Hospital and the National Heart Hospital in a period extending up to April 1971.

There were 34 men and four women ranging in age from 24 to 71 years with an average age of 50 years.

All patients were severely symptomatic and disabled before surgery. The duration of symptoms varied between six months and 15 years. A previous history

1Reprim requests to L. Gonzalez-Lavin, M.D., Department of Surgery, Institute of Cardiology, 35 Wimpole Street, London W1M 8EX of myocardial infarction was given by 20, 12 of whom had had multiple infarctions. A family history of coronary artery disease was given by 10 patients.

A preoperative electrocardiogram was reported as normal in 11 patients ; 19 showed evidence of previous myocardial infarction. The remaining eight ECGs were considered abnormal but not characteristic of infarction.

Coronary arteriography was performed in all patients. Seventy-five per cent obstruction of one or more major vessels was present in 23, and $90 \%$ obstruction was present in the other 15 . In addition, four patients had left ventricular aneurysms and five others had well-defined areas of akinesia of the left ventricle (Fig. 1).

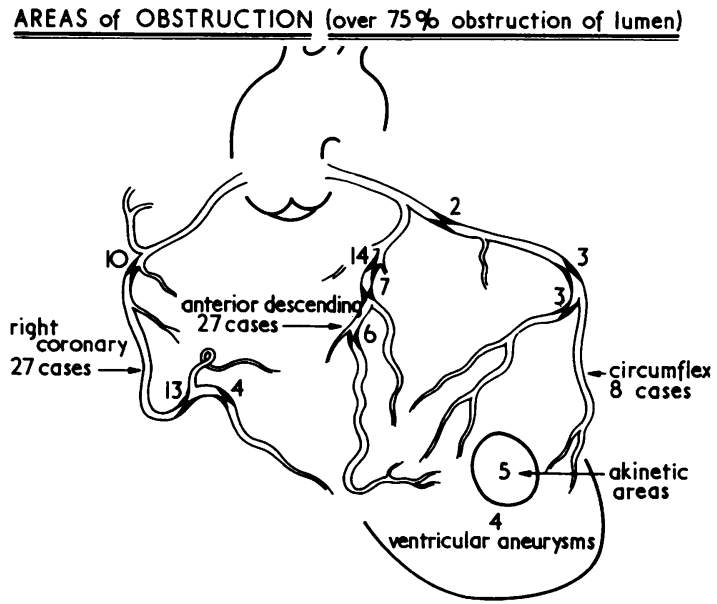

FIG. 1. See text. 


\section{SURGICAL TECHNIQUE}

A midline sternotomy gives the best exposure of the heart and coronary vessels. While the chest is being opened, one or both long saphenous veins are excised through multiple small incisions (Effler, Favaloro, and Groves, 1970 ; Johnson, Flemma, Lepley, and Ellison, 1969).

After heparinization the ascending aorta and both venae cavae are cannulated. The heart is carefully inspected to detect areas of akinesia. All three main coronary vessels are palpated. A segment is then selected for the anastomosis in the affected vessel or vessels.

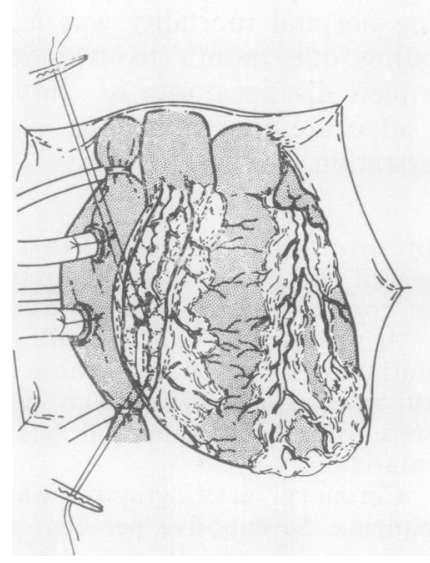

FIG. 2. See text.

High-flow normothermic cardiopulmonary bypass is then established using haemodilution and a bubble oxygenator and a vent is placed in the left ventricle to decompress the heart. Exposure of the right coronary artery is excellent (Fig. 2) and displacement of the heart is not necessary unless the anastomosis is being performed on the posterior aspect. It is usually necessary to displace the heart towards the right to approach the anterior descending and circumflex coronary arteries. This is easily accomplished by placing two large swabs posteriorly in the pericardial cavity.

Two 2-0 silk sutures are placed around the coronary vessel, one proximal and the other distal to the area selected for the arteriotomy. Gentle traction of these sutures is sufficient to control bleeding after the vessel has been incised. Two interrupted sutures of 6-0 Mersilene are then placed through the adventitia of the vessel at the level where the incision is to be made. The artery is better exposed by placing gentle traction on these sutures.
The initial incision is made with a no. $15 \mathrm{knife}$ blade and is enlarged with Potts scissors. The length of the incision varies between 0.8 and $1 \mathrm{~cm}$ (Fig. 3-1).

The adventitia is dissected away from the saphenous vein and both ends of the vein are prepared for the anastomosis. They are transected at a $45^{\circ}$ angle and the opening is enlarged by a longitudinal incision. The vein is always placed in a reversed position to allow an uninterrupted blood flow (Fig. 3-2). The distal anastomosis between the coronary vessel and the vein is done first. When the artery is small or irregular, due to multiple atherosclerotic plaques, a small metal

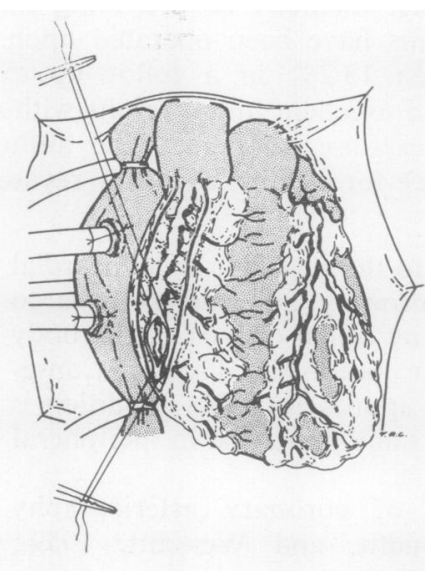

probe is inserted distally into the lumen of the vessel and the anastomosis is performed with multiple interrupted stitches of 6-0 Mersilene. In some cases the arterial lumen is large enough for

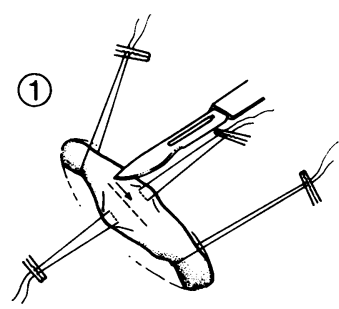

(2)

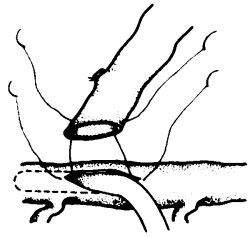

(3)

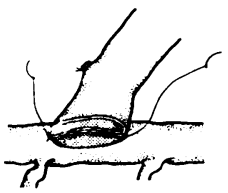

(4)

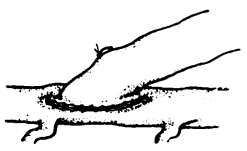

FIG. 3. See text. 
the anastomosis to be performed with a running stitch of the same material (Fig. 3-3 and 4). To facilitate the surgical manoeuvres, anoxic arrest is employed for up to 15 minutês. If a longer time is required, we prefer to induce ventricular fibrillation and perfuse the myocardium.

The aortic area of the proximal anastomosis is selected after placing the vein in a 'comfortable' position so as to avoid kinks or acute angulation of the graft. A vascular clamp is placed on the ascending aorta to exclude part of the vessel; a small piece of the aortic wall is excised and the proximal anastomosis is then performed with a continuous suture of $6-0$ silk.

When present, a left ventricular aneurysm is usually well delineated and excision is easily performed (Fig. 4). The ventricular incision is then closed in two layers (Fig. 5), reinforcing the suture line with two strips of Teflon felt. The air is evacuated from the left ventricular cavity and bypass is gradually discontinued, allowing the heart to take over the load of the circulation. Atrial and ventricular pacing wires are implanted. The pericardium is loosely approximated and the chest is closed in layers.

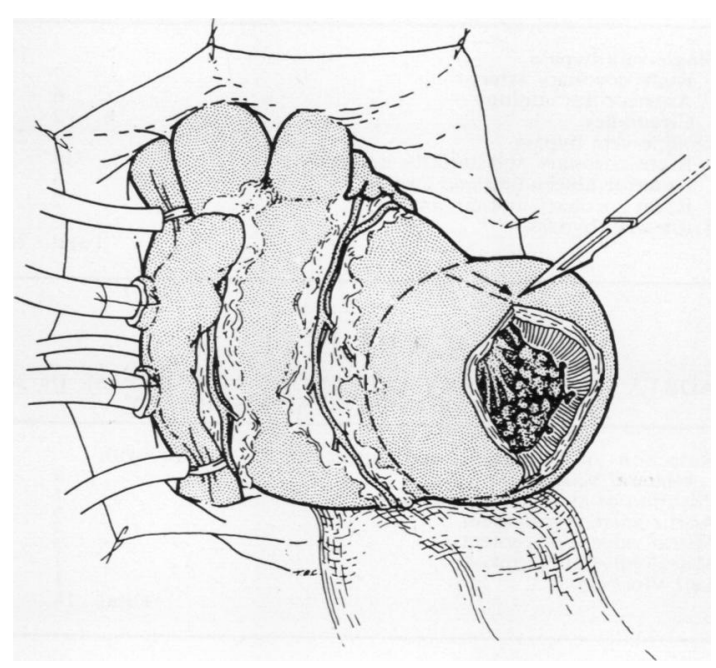

FIG. 4. See text.

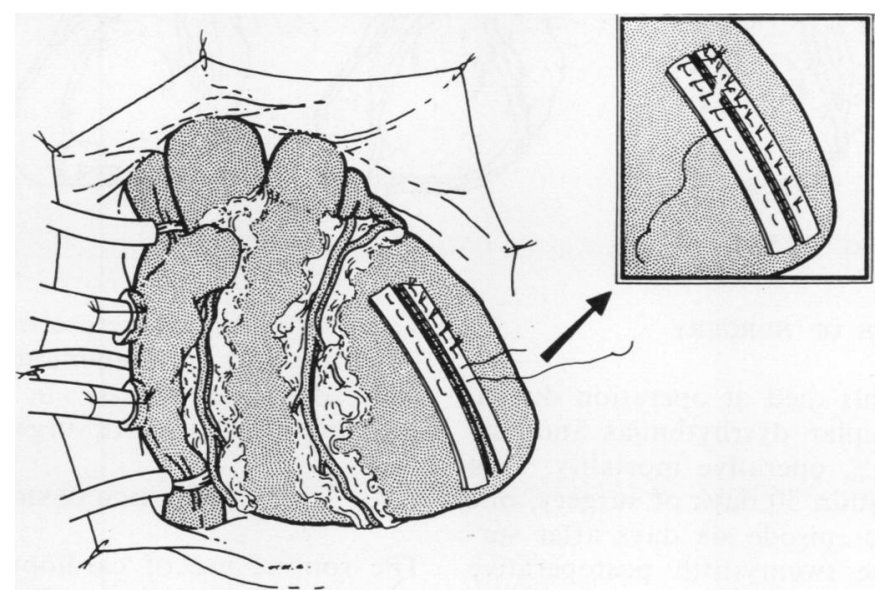

FIG. 5. See text.

\section{ANALYSIS OF SURGERY}

Fifteen patients underwent a single-vein bypass (Fig. 6) and 22 had a double-vein bypass (Fig. 7). The remaining patient underwent a triple-vein bypass (Table I). Sixty-two of the anastomoses between the vein and the coronary artery were performed end-to-side. Three patients had side- to-side and end-to-side anastomoses between the saphenous vein and two different segments of the coronary arteries. The remaining one had an endto-end anastomosis to the right coronary artery. The anastomosis was performed with interrupted sutures in the first 25 patients. Running sutures were employed in the last 13 . Fifteen of the 38 patients had additional surgery (Table II). 
T A B L E I

AORTA TO CORONARY SAPHENOUS VEIN BYPASS: SURGICAL PROCEDURE IN 38 PATIENTS

\begin{tabular}{|c|c|c|c|c|c|c|c|}
\hline \multicolumn{7}{|l|}{ Single-vein bypass } & \multirow{2}{*}{15} \\
\hline Right coronary artery & . & . & . & .. & $\cdots$ & 7 & \\
\hline Anterior descending & . & . & . & $\ldots$ & $\ldots$ & 6 & \\
\hline Circumflex $\quad \ldots$ & $\ldots$ & .. & .. & $\ldots$ & $\ldots$ & 2 & \\
\hline \multirow{2}{*}{\multicolumn{7}{|c|}{$\begin{array}{l}\text { Double-vein bypass } \\
\text { Right coronary and anterior descending } \ldots\end{array}$}} & 22 \\
\hline & & & . & . & & 17 & \\
\hline & .. & . . & & 3 & \\
\hline \multicolumn{2}{|c|}{$\begin{array}{l}\text { Right coronary and circumflex } \\
\text { Triple-vein bypass }\end{array}$} & . . & .. & .. & & 2 & \\
\hline & & & & & \multicolumn{2}{|c|}{ Total } & 38 \\
\hline
\end{tabular}

T A B L E I I

AORTA TO CORONARY SAPHENOUS VEIN BYPASS IN 38 PATIENTS: CONCOMITANT SURGERY Resection of left ventricular aneurysm (1 patient with
bilateral Vineberg) Plication of akinetic areas of $\mathbf{L} . \mathbf{V}$. Aortic valve replacement Mitral valve replacement Mitral valve annuloplasty Left Vineberg

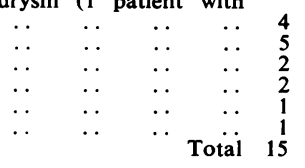

22

1
38

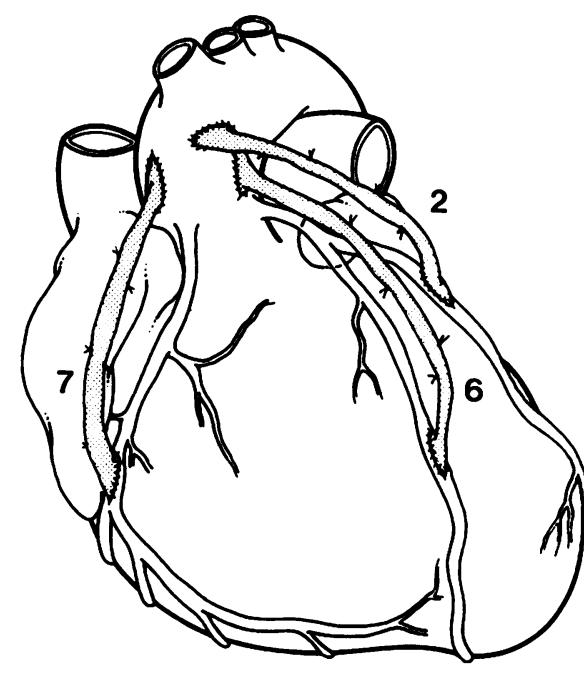

FIG. 6. See text.

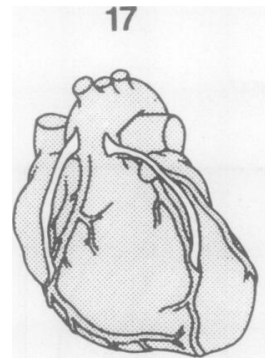

FIG. 7. See text.

\section{RESULTS OF SURGERY}

Two of the 38 patients died at operation due to uncontrollable ventricular dysrhythmias and low cardiac output, a $5.3 \%$ operative mortality. Two more patients died within 30 days of surgery, one due to an arrhythmic episode six days after surgery and one on the twenty-fifth postoperative day due to a massive myocardial infarction. A third patient succumbed six weeks after surgery to multiple ventricular arrhythmias and low cardiac output. No further deaths have occurred in a follow-up extending for one month to two years. The total mortality is $13 \cdot 2 \%$.

Among the 33 survivors, 31 had excellent results with complete disappearance of symptoms and marked improvement in exercise tolerance. Two patients had no improvement at all and in both cases the vein bypass to the right coronary artery was found to be thrombosed on re-investigation.
These two patients were operated on early in this series without cardiopulmonary bypass and both had additional disease in anterior descending coronary arteries where surgery was not attempted.

\section{DISCUSSION}

The routine use of cardiopulmonary bypass has greatly facilitated the application of this surgical technique to all main coronary vessels and most of their major branches (Adam, Mitchel, and Lambert, 1970 ; Effler et al., 1970 ; Favaloro, 1968 ; Favaloro et al., 1970a, 1970b ; Johnson, Flemma, and Lepley, 1970b ; Johnson and Lepley, 1970). This procedure can be accomplished with an acceptable operative mortality (Edwards, Jones, Dear, and Kerr, 1970 ; Effler, 1969a, b ; Green, Spencer, Tice, and Stertzer, 1970 ; Mitchel et al., 1970). It is adaptable for all major coronary arteries, provides an immediate augmentation of 
coronary blood flow with instant improvement in myocardial perfusion (Johnson et al., 1970a ; Johnson, Flemma, Manley, and Lepley, 1970c), and it is usually followed by a dramatic relief of symptoms.

In conclusion, in the light of our experience and that of others (Adam et al., 1970 ; Edwards et al., 1970 ; Effler, 1969a ; Effler, 1969b ; Effler et al., 1970 ; Favaloro, 1968 ; Favaloro, 1969 ; Favaloro et al., 1970a ; Favaloro et al., 1970b ; Green et al., 1970 ; Johnson et al., 1969 ; Johnson et al., 1970b ; Johnson and Lepley, 1970 ; Johnson et al., 1970a ; Johnson et al., 1970c ; Mitchel et al., 1970) the use of vein bypass grafts for the treatment of occlusive coronary artery disease appears promising and merits continued application.

We wish to thank Miss R. Craddock for the diagrams appearing in this article and Miss V. Adler for assistance in the preparation of the manuscript.

\section{REFERENCES}

Adam, M., Mitchel, B. F., and Lambert, C. J. (1970). Immediate revascularization of the heart. Circulation, 41, Suppl. II, p. 73.

Edwards, W. S., Jones, W. B., Dear, H. D., and Kerr, A. R. (1970). Direct surgery for coronary artery disease: Technique for left anterior descending coronary artery bypass. J. Amer. med. Ass., 211, 1182.

Effler, D. B. (1969a). Myocardial revascularization surgery. Surgery Annual, edited by P. Cooper, Vol. 1, p. 413. Appleton-Century-Crofts, New York.

(1969b). Myocardial revascularization. Current status and trends. In Cardiovascular Surgery, Current Practice, edited by T. H. Burford and T. B. Ferguson, C. V. Mosby, St. Louis. Vol. 1, p. 195.

, Favaloro, R. G., and Groves, L. K. (1970). Coronary artery surgery utilizing saphenous vein graft techniques. Clinical experience with 224 operations. J. thorac. cardiovasc. Surg., 59, 147.
Favaloro, R. G. (1968). Saphenous vein autograft replacement of severe segmental coronary artery occlusion. Operative technique. Ann. thorac. Surg., 5, 334.

(1969). Saphenous vein graft in the surgical treatment of coronary artery disease. J. thorac. cardiovasc. Surg., $58,178$.

- Effler, D. B., Groves, L. K., Sheldon, W. C., Shirey, E. K., and Sones, M. F., Jr. (1970a). Severe segmental obstruction of the left main coronary artery and its divisions. Surgical treatment by saphenous vein graft technique. J. thorac. cardiovasc. Surg., 60, 469.

myocardial revascularization by saphenous vein graft. Present operative technique and indications. Ann. thorac. Surg., 10, 97.

Green, G. E., Spencer, F. C., Tice, D. A., and Stertzer, S. H. (1970). Arterial and venous microsurgical bypass grafts for coronary artery disease. J. thorac. cardiovasc. Surg., 60, 491.

Johnson, W. D., Flemma, R. J., Harding, H. W., Cooper, G. N., Jr., and Lepley, D., Jr. (1970a). Surgical principles in the direct reconstruction of left coronary flow. Ann. thorac. Surg., 10, 141.

—_ and Lepley, D., Jr. (1970b). Direct coronary surgery utilizing multiple-vein bypass grafts. Ann. thorac. Surg., 9, 436.

$-\longrightarrow$ and Ellison, E. H. (1969). Extended treatment of severe coronary artery disease: A total surgical approach. Ann. Surg., 170, 460.

_- Manley, J. C., and Lepley, D., Jr. (1970c). The physiologic parameters of ventricular function as affected by direct coronary surgery. J. thorac. cardiovasc. Surg., 60, 483.

- and Lepley, D. (1970). An aggressive surgical approach to coronary disease. J. thorac. cardiovasc. Surg., 59, 128.

Mitchel, B. F., Adam, M., Lambert, C. J., Sungu, U., and Shiekh, S. (1970). Ascending aorta-to-coronary artery saphenous vein bypass grafts. $J$. thorac. cardiovasc. Surg., 60, 457.

Sones, F. M., Jr., and Shirey, E. K. (1962). Cine coronary arteriography. Mod. Conc. cardiovasc. Dis., 31, 735.

- Proudfit, W. L., and Westcott, R. N. (1959). Cine-coronary arteriography. Circulation, 20, 773. 